\title{
Depression among Residents of Free and Pay Stay Care Homes for the
} Aged

\section{Suresh $\mathrm{K}^{*}$ and Jamuna D}

Department of Psychology, Centre for Research on Ageing, Sri Venkateshwara University, Tirupati, Andhra Pradesh, India

\begin{abstract}
One of the mental health concerns during later part of adulthood is depression. Reviews on gerontological researches shows that there is a dearth of researches in this area. Thus, an attempt is made in this study to assess the levels of depression and depressive mood in a sample of 200 residents of free and pay and stay homes for the aged located in United Andhra Pradesh. Level of depression and nature and frequency pregnancy of depressive mood among residents were recorded by using an adapted version of geriatric depression scale. Results on depression among residents are discussed across socio-demographic subgroups. Mental health care policy implications are discussed.
\end{abstract}

Keywords: Depression; Senior care homes; Socio-demographic variables

\section{Introduction}

Depression is common in the elderly and is a major public health problem. The WHO in 2005 also emphasizes that depression, which is the fourth most common illness, can lead to emotional, physical, economic, and social problems (World Health Organization). The prevalence rate of depression varies worldwide, and their prevalence rates range between $10 \%$ and $55 \%$. A study shows the depression ranges from $34.6 \%$ to $77.5 \%$ in old age home [1].

Depression in late life is associated with significant morbidity, including deficits in a range of cognitive functions and considerable influence on functional impairment, disability [2], decreased quality of life, and has a negative effect on the body's recovery from illness, increases the rate of suicide, increases use of health care services and expenses and can result in early death and disturbance in the general state of wellness [3]. Depressive symptoms are associated with greater impairment and decreased quality of life among patients with coexisting chronic illnesses, such as emphysema, cancer, and diabetes. When depression coexists with other medical conditions, the resulting disability appears to be additive. However, even in older adults without a disability, depression significantly increases the risk for subsequent incident ADL and mobility disability. Studies have estimated that "elderly persons with depressive symptoms accrued 50\% higher healthcare costs from more frequent use of medical services" than do other older adults not suffering from depression [4].

A number of factors have been associated with late-life depression because many of these factors, such as illness and loss of family, friends, social support or independence, are common among older people [5]. It is sometimes assumed that depression is a natural part of aging. There is, in fact, continuing debate as to how depression relates to aging. Diagnosis of depression has been reported to increase with age up to 65 years and then decrease in prevalence [6]. Some studies suggest that depression sometimes goes unidentified and untreated in elderly individuals, including those in long-term care homes [7]. In studies of depression and mortality, the odds of dying were 1.5 to 2 times greater in elderly people with depression compared to those without depression [8].

Older adults living in senior care homes are more vulnerable to healthrelated problems including mental health problems. Various prevalence studies have reported mental health problems among residents of senior care homes. Researches on mental health and life in old age homes demonstrated that depression, maladjustment, worry, psychosomatic distress, loneliness and other psychological problems $[9,10]$.

Periodical Reviews on Indian gerontology and gero-psychology indicate that one of the gray areas in gerontology is mental health of residents living in senior care homes [11,12]. In view of this, an attempt was made through the present study to examine the depression among residents of free and pay and stay senior care homes located in united Andhra Pradesh.

\section{Method}

\section{Sample}

A sample of 200 residents living in free and pay and stay senior care homes of united Andhra Pradesh from the age groups of 60-69, and 70-79 years were drawn by using a multi-stage random sampling technique. After obtaining formal permission from the authorities of senior care homes, 100 older adult residents from free care homes for seniors and 100 older adult residents from pay and stay senior care homes with 10 from each home $(10 \times 10$ homes $)$ were identified at random. The subjects without chronic illness and those cognitively intact were included in the study. The subjects in the study were individually contacted and tests were administered in one session if they were willing to participate. Personal Data Form (PDF) was used to seek information on relevant socio-demographic characteristics of participants. Geriatric Depression Scale (GDS) was used to assess depression levels in the elderly. In the present study, the short form, GDS-15 was used. The 15 item GDS-15 has been translated to Telugu, the regional language and was administered to 30 Indian older adults $(\mathrm{N}=30)$ with an interval of 10 days. The test-retest reliability of GDS15 was 0.87 . The influence of certain socio-demographic variables on dependent variable depression was tested through a simple ' $t$ ' tests.

\section{Results and Discussion}

In this subsection, the data pertaining to depression in various

*Corresponding author: Suresh K, Department of Psychology, Centre for Research on Ageing, Sri Venkateshwara University, Tirupati, Andhra Pradesh, India, Tel: +91-9052072050; E-mail: suresh108svu@gmail.com

Received July 23, 2018; Accepted August 28, 2018; Published August 31, 2018

Citation: Suresh K, Jamuna D (2018) Depression among Residents of Free and Pay Stay Care Homes for the Aged. J Gerontol Geriatr Res 7: 480. doi:10.4172/21677182.1000480

Copyright: @ 2018 Suresh K, et al. This is an open-access article distributed under the terms of the Creative Commons Attribution License, which permits unrestricted use, distribution, and reproduction in any medium, provided the original author and source are credited. 
Citation: Suresh K, Jamuna D (2018) Depression among Residents of Free and Pay Stay Care Homes for the Aged. J Gerontol Geriatr Res 7: 480. doi:10.4172/2167-7182.1000480

Page 2 of 3

\begin{tabular}{|c|c|c|c|c|}
\hline S. No & Category & $\mathbf{N}$ & Mean (SD) & t-value \\
\hline \multirow{3}{*}{1} & & & & \\
\hline & $60-65$ & 50 & $43.62(4.59)$ & \multirow{2}{*}{$1.981^{*}$} \\
\hline & $66-70$ & 50 & $45.16(3.01)$ & \\
\hline \multirow{3}{*}{2} & \multicolumn{3}{|c|}{ Gender } & \multirow{3}{*}{$1.984^{*}$} \\
\hline & Male & 50 & $44.78(4.32)$ & \\
\hline & Female & 50 & $43.20(3.61)$ & \\
\hline \multirow{3}{*}{3} & & & & \\
\hline & No education & 74 & $44.12(3.34)$ & \multirow{2}{*}{$1.988^{*}$} \\
\hline & Primary & 26 & $45.62(3.15)$ & \\
\hline \multirow{3}{*}{4} & & & & \\
\hline & Widowed & 23 & $41.78(1.88)$ & \multirow{2}{*}{$1.984^{*}$} \\
\hline & Married but single & 77 & $42.70(1.96)$ & \\
\hline \multirow{3}{*}{5} & & & & \\
\hline & Poor & 56 & $41.57(3.08)$ & \multirow{2}{*}{$1.984^{*}$} \\
\hline & Lower income & 44 & $42.61(1.83)$ & \\
\hline
\end{tabular}

Table 1: Status of depression in residents of different socio-demographic subgroups in free senior care homes $(N=100)$.

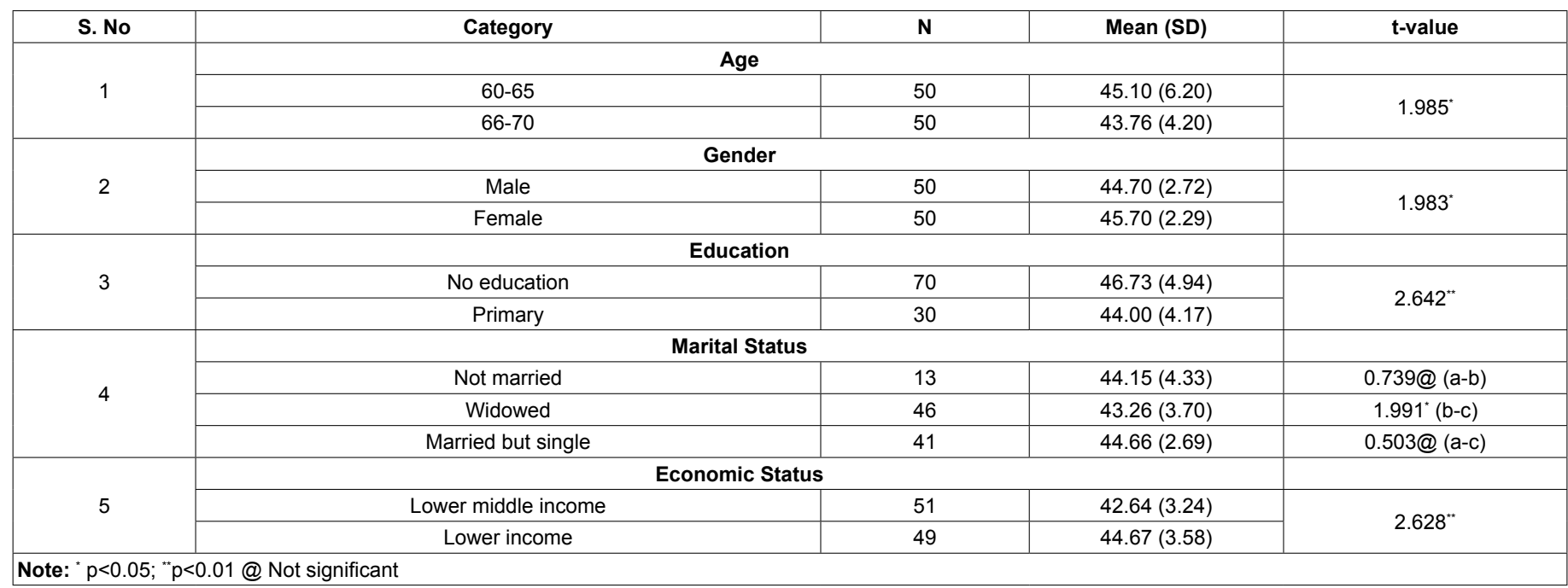

Table 2: Status of depression in residents of different socio-demographic sub-groups in pay and stay senior care homes ( $\mathrm{N}=100)$.

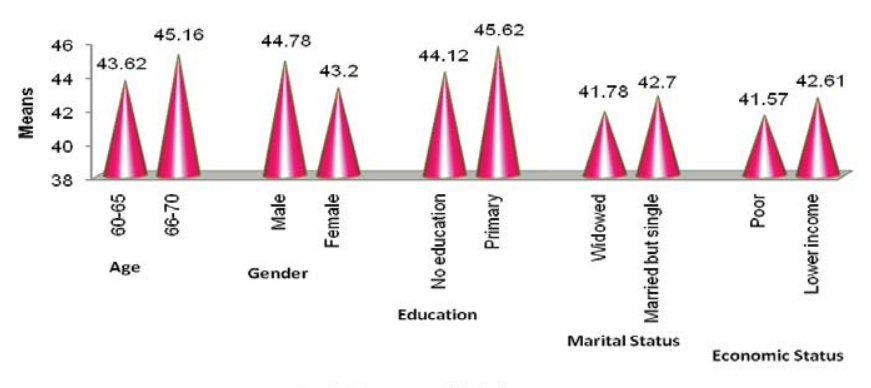

Socio-Demographic Subgroups

Figure 1: Depression in residents of different socio-demographic subgroups of free senior care homes.

socio-demographic subgroups were analyzed. For purposes of parsimony, a representative sample of 200 residents from free and pay and stay senior care homes were identified and an attempt has been made to examine the socio-demographic subgroup differences by using simple ' $t$ ' tests. An attempt has been made to examine the mean trends in the status of depression in residents of free senior care homes and

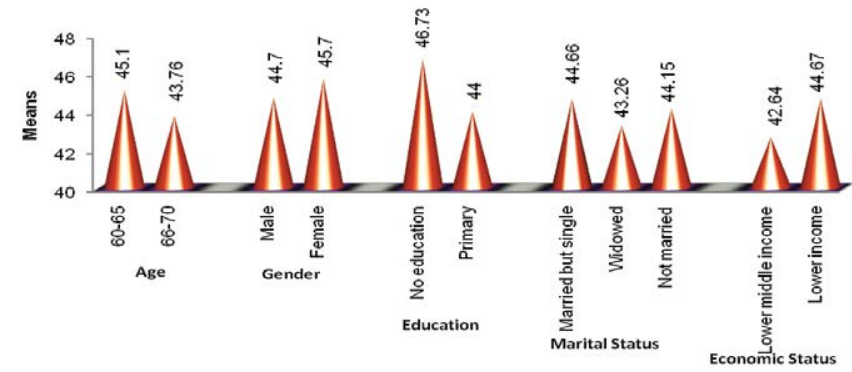

Figure 2: Depression in residents of different socio-demographic sub-groups pay and stay senior care homes.

pay and stay senior care homes across different socio demographic subgroups (Tables 1 and 2).

The levels of depression were assessed by using a Geriatric Depression scale. The score on this scale is an indication of presence or absence of symptoms related to depressive mood. The mean trends in different age, gender, education, marital status and economic status indicate that the 
subgroup mean differences are statistically significant. The magnitude of mean differences is not high but statistically they found to be significant. The magnitude of levels of depression were found to be slightly higher in 66-70 years residents, male older adults, residents with primary education, widowed elderly and incumbents from lower income group compared to their other counterparts in free homes.

Similar to the above, analysis has been carried out on levels of depression in different social-demographic subgroups of residents living in pay and stay senior care homes (Table 2).

The mean differences of age, gender, education, marital status and income subgroups differed significantly. However, in the subgroup not married and widowed subgroup differences $(\mathrm{t}=0.739)$ and subgroups not married and married but single did not differ statistically $(t=0.503)$. Thus, though the quantum of mean differences was low but most of the subgroup differences were statistically significantly. In terms of mean scores, it is evident that residents in 60-65 years, those who were female, residents with no education, not married and married but single (living alone) and lower income incumbents of pay and stay reported slightly higher levels of depression compared to those who were in 66-70 years, male, residents with primary education, widowed and incumbents from lower middle class. Diagrammatic illustrations of mean trends of depression in different socio-demographic subgroups are given in Figures 1 and 2.

This finding is consistent with previously reported data [13]. There are significant clinical, fiscal and quality-of-life consequences related to a combined prevalence of depression diagnoses and symptoms approaching one-half of seniors in residential care. This study confirmed previous research findings that rates of a depression diagnosis decline after the age of 65 . However, the analysis also revealed that symptoms of depression in the absence of a diagnosis increased after this age. There are many individual and system-level factors contributing to non-diagnosis of depression in seniors [14]. One possible explanation is that the criteria physicians use to arrive at a diagnosis of depression do not capture some of the elderly people suffering from clinically significant symptoms of depression. Many older people do not identify depressed mood as a symptom; instead, they may complain of physical symptoms or that they simply have no pleasure in their lives [15-20].

\section{Conclusions}

- Findings on depression highlight the need for planning of Interventions and to cope with the psychological problems and depression.

- The outcome of the study highlights the need for awareness programmes for elderly in promoting physical and mental wellbeing.

- The findings suggest that there is a dire need for a community mental health worker who can be identified from village/mandal level and could act as a link between community living older adults and health care providers.

\section{References}

1. Weyerer S, Mann AH, Ames D (1995) Prevalence of depression and dementia in residents of old age homes in Mannheim and Camden (London). Z Gerontol Geriatr 28: 169-178.

2. Tam CWC, Chiu HFK (2011) Depression and suicide in the elderly. The Hong Kong Medial Diary, Medical Bulletin 16: 13-15.

3. Serby M, Yu M (2003) Overview: Depression in the elderly. Mount Sinai Journal of Medicine 70: 38-44.

4. Katon WJ (2008) The comorbidity of diabetes mellitus and depression. The American Journal of Medicine 121: S8-S15.

5. Blazer DG (2003) Depression in late life: review and commentary. Journals of Gerontology Series A-Biological Sciences \& Medical Sciences 58: 249-265.

6. Hasin DS (2005) Epidemiology of major depressive disorder: results from the national epidemiologic survey on alcoholism and related conditions. Arch Gen Psychiatry 62: 1097-1106.

7. Djernes JK (2006) Prevalence and predictors of depression in populations of elderly: A review. Acta Psychiatr Scand 113: 372-387.

8. Schulz R (2000) Association between depression and mortality in older adults: The cardiovascular health study. Archives of Internal Medicine 160: 1761-1768.

9. Chandrika P, Anantharaman RN (1982) Life changes and adjustment in old age. Journal of Psychological Research 26: 137-141.

10. Jamuna D, Ramamurti PV, Kalavar JM (2005) Old age homes: The experience of elderly in Bangalore, India. International Journal of the Aging Family system 1: $21-36$.

11. Ramamurti PV, Jamuna D (1995) Perspectives of gero-psychology in India: A review. Indian Psychological Abstracts and Reviews 2: 207-267.

12. Ramamurti PV, Liebig S Phoebe, Jamuna D (2015) Gerontology in India- A spotlight article on India. The Gerontologist 55: 894-900.

13. Hybels CF, Blazer DG (2003) Epidemiology of late-life mental disorders. Clinics in Geriatric Medicine 19: 663-696.

14. Martin L (2008) Predictors of a new depression diagnosis among older adults admitted to complex continuing care: implications for the depression rating scale (DRS). Age Ageing 37: 51-56.

15. Gallo JJ (1997) Depression without sadness: Functional outcomes of nondysphoric depression in later life. J Am Geriatr Soc 45: 570-578.

16. Dhara RD, Jogsan YA (2013) Depression and psychological well-being in old age. Journal of Psychology \& Psychotherapy 3: 117.

17. Langa KM, Valenstein MA, Fendrick AM (2004) Extent and cost of informal caregiving for older Americans with symptoms of depression. American Journal of Psychology 161: 857-863.

18. Worley H (2006) Depression: A leading contributor to global burden of disease

19. Mathew MA, George LS, Paniyadi N (2009) Comparative study on stress coping strategies and quality of life of institutionalized and non-institutionalized elderly in Kottayam district Kerala. Indian Journal of Gerontology 23: 79-87.

20. World Health Organization (2001) Strengthening mental health promotion Geneva, Switzerland. 